\title{
Prefeitos de capitais de famílias políticas eleitos em 2016
}

\section{Ricardo Costa de Oliveira ${ }^{1}$}

\begin{abstract}
RESUMO: Investigamos a presença e a atuação política dos candidatos a prefeitos eleitos nas prefeituras das capitais em 2016. Desenvolvemos uma pesquisa qualitativa com a biografia, trajetória e genealogia dos principais eleitos nas capitais dos estados brasileiros em 2016. De que maneira capitais sociais, políticos e familiares contribuem no sucesso eleitoral de candidatos com famílias políticas, genealogias tradicionalmente estabelecidas na classe dominante e nas elites políticas.
\end{abstract}

Palavras-chave: Prefeitos Capitais Brasil. Eleições 2016. Sociologia Política.

\section{Mayors of capitals of political families elected in 2016}

\begin{abstract}
We investigated the presence and the political activities of the candidates for mayors elected in the prefectures of capitals in 2016. We developed a qualitative research with the biography, trajectory and genealogy of the main elected ones in the capitals of the Brazilian states in 2016. In what way social, political capitals And family members contribute to the electoral success of candidates with political families, genealogies traditionally established in the ruling class and political elites.
\end{abstract}

Keywords: Mayors Capitals Brazil. Elections 2016. Political Sociology.

- Enviado em 01/05/2017

- Aprovado em 17/05/2017

\footnotetext{
${ }^{1}$ Professor Associado. Departamento de Sociologia. UFPR. Uma versão preliminar desse texto foi apresentada no VIII Seminário Nacional de Sociologia e Política realizado de 17 a 19 de maio de 2017 na UFPR. E-mail: E-mail: rco2000@uol.com.br
} 


\section{INTRODUÇÃO}

Qualquer instituição política no Brasil terá boa parte dos seus participantes políticos oriundos de famílias políticas. Aplicamos a teoria do nepotismo para entendermos e classificarmos os prefeitos das capitais eleitos em 2016. A teoria do nepotismo aponta a necessidade e importância das famílias na formação do poder político no Brasil contemporâneo, uma vez que a unidade organizacional da política no Brasil ainda é a família preferencialmente. Procuraremos demonstrar como as estruturas de parentesco ainda constituem muitas das principais trajetórias políticas de sucesso no Brasil. Esta agenda de pesquisa segue sendo desenvolvida coletivamente pelo pesquisador Ricardo Costa de Oliveira, pelo Núcleo de Estudos Paranaenses da Universidade Federal do Paraná (NEP-UFPR)² e por autores como José Marciano Monteiro ${ }^{3}$, da Universidade Federal de Campina Grande.

A base conceitual opera categorias e conceitos como os de família, biografia, trajetória, capital social, prosopografia, espírito de família, "habitus" de classe e família como negócio.

\section{PREFEITOS ELEITOS E FAMÍLIAS}

- Nelson Marchezan Júnior - PSDB - Porto Alegre. Filho do ex-deputado Federal Nelson Marchezan Arena, PDS, PPR e PSDB. Presidente da Câmara dos Deputados entre 1981-1983.

- Gean Marques Loureiro - PMDB - Florianópolis. “No gabinete do Jorginho Mello (PSDB, presidente da Casa) o primeiro nome da lista é o de Aguinaldo José Loureiro. Pra quem não conseguiu unir o nome ao sobrenome, trata-se do pai do presidente da Câmara de Vereadores de

\footnotetext{
2 Revista NEP - Núcleo de Estudos Paranaenses da UFPR. Volume 2. Número 4. Famílias Políticas e Desempenho Eleitoral nas Eleições de 2014. Família como variável política nas eleições Ricardo Costa de Oliveira. http://revistas.ufpr.br/nep/article/view/48631. Na Teia do Nepotismo: Sociologia Política das relações de parentesco e poder político no Paraná e no Brasil. Insight. 2012. Curitiba.

${ }^{3}$ A Política Como negócio de Família. José Marciano Monteiro. 2017. LiberArs.
} 
Florianópolis, Gean Marques Loureiro (PMDB). Transparência tem dessas coisas... Por Cesar Valente $\cdot 18$ de agosto de $2009^{4 \prime \prime}$

- Rafael Greca de Macedo - Curitiba - membro da família histórica Macedo da classe dominante tradicional do Paraná ${ }^{5}$.

- João Agripino da Costa Doria Junior - São Paulo - filho do publicitário e ex-deputado federal baiano João Doria e da empresária paulista Maria Sylvia Vieira de Moraes Dias Doria. Família bem posicionada desde o período colonial. Descende dos Costa Doria, uma família brasileira do período colonial, cujos membros foram senhores de engenhos, militares e políticos da Bahia e Sergipe ${ }^{6}$.

- Marcelo Bezerra Crivella - PRB - Rio de Janeiro. Filho de Eris Bezerra Crivella e Mucio Crivella. Sobrinho de Edir Macedo Bezerra. Romildo Ribeiro Soares conheceu Edir Macedo na Igreja Pentecostal Nova Vida, casou-se com a irmã de Macedo, Maria Magdalena Bezerra

- Alexandre Kalil - PHS - Belo Horizonte - Filho do ex-presidente do Clube Atlético Mineiro Elias Kalil. Empresário e futebol ${ }^{8}$.

- Luciano Santos Rezende ${ }^{9}$ - PPS - Vitória.

- Marcos Marcello Trad - PSD - Campo Grande - Filho do ex-deputado federal Nelson Trad e de Therezinha Mandetta, irmão do ex-prefeito de Campo Grande, Nelson Trad Filho, e do exdeputado federal Fábio Trad ${ }^{10}$.

\footnotetext{
${ }^{4}$ http://www.deolhonacapital.com.br/2009/08/18/transparencia-tem-dessas-coisas/ - Floripa

${ }^{5}$ Ricardo Costa de Oliveira. O Silêncio dos Vencedores. Moinho do Verbo. 2001. Curitiba.

${ }^{6}$ Francisco Antonio Doria, De Gênova ao Brasil, I - Costa Doria, Rocha Doria, Lucatelli Doria. Bingen, 2002

${ }^{7}$ http://dicionariompb.com.br/bispo-marcelo-crivella/biografia

8 https://eleicoes.uol.com.br/2016/noticias/2016/10/30/bh-repete-sao-paulo-e-nao-politico-kalil-e-eleitoprefeito.htm

${ }^{9}$ http://reporterpaulomaciel.blogspot.com.br/2009/08/luciano-rezende-visita-sao-roque-do.html
} 
- Emanuel Pinheiro - PMDB - Cuiabá - É filho do ex-deputado Emanuel Pinheiro da Silva Primo (ARENA) e de Dona Maria Helena de Freitas. É casado com Márcia Khun Pinheiro e tem dois filhos.

- Iris Rezende Machado - PMDB - Goiânia. Mulher Iris de Araújo Rezende Machado foi Deputada Federal.

- Antonio Carlos Magalhães Neto - DEM - Salvador. É neto do falecido Antônio Carlos Magalhães (ACM), sobrinho de Luís Eduardo Magalhães e filho de Antônio Carlos Magalhães Júnior (diretor da Rede Bahia), e herdeiro político de uma das mais tradicionais famílias políticas do país. Foi noivo da brasiliense Tata Canhedo, herdeira do Grupo Canhedo e neta de Wagner Canhedo. Foi eleito prefeito de Salvador em 2012 e reeleito em 2016.

- Edvaldo Nogueira - PCdoB - Aracaju.

- Rui Soares Palmeira - PSDB - Maceió. Avô paterno Rui Soares Palmeira que foi eleito deputado federal constituinte de 1946 e senador, o pai Guilherme, prefeito de Maceió, deputado estadual, governador, senador e ministro do TCU. Ambos com carreiras políticas em Alagoas seguidas pelo herdeiro, com exceção do tio Vladimir Palmeira, no Rio de Janeiro, como deputado federal.

- Geraldo Júlio de Mello Filho - PSB - Recife. Carreira técnica e política ${ }^{11}$. Mãe do prefeito Maria Angela de Abreu e Lima Mello com cargo comissionado na Secretaria de Educação, Gerente Financeira.

- Luciano Cartaxo Pires de Sá - PSD - João Pessoa. Farmacêutico.

10 http://www.caaraponews.com.br/noticia/50353/a-grande-familia-bons-de-voto-clas-se-perpetuam-na-politica-de$\mathrm{ms}$

11 http://blogs.ne10.uol.com.br/jamildo/2016/03/09/mae-de-geraldo-julio-ocupa-gerencia-financeira-na-secretariade-educacao-de-paulo-camara/ 
- Carlos Eduardo Alves - PDT - Natal. Filho do ex-prefeito do município, Agnelo Alves. É sobrinho do ex-governador e ex-ministro de estado Aluísio Alves. É também primo do ex-governador do Rio Grande do Norte Garibaldi Alves Filho, outro sobrinho de Aluísio Alves.

- Roberto Cláudio Rodrigues Bezerra - PDT - Fortaleza. Filho do ex-reitor da Universidade Federal do Ceará Roberto Cláudio Frota Bezerra, Cláudio é médico sanitarista com PhD em saúde pública pela Universidade do Arizona.

- Firmino da Silveira Soares Filho ${ }^{12}$ - PSDB - Teresina. Carreira técnica e política.

- Edivaldo de Holanda Braga Júnior - PDT - São Luís - Pai foi vereador (1977-1983), deputado federal (1988-1990) e foi deputado estadual (1983-1987, 2007-2010, 2011-2013).

- Zenaldo Rodrigues Coutinho Júnior - PSDB - Belém - nomeou o próprio irmão, Augusto Cesar Neves Coutinho, como Secretário Municipal de Administração (Semad) ${ }^{13}$. "Além disso, nomeou ainda, no mesmo decreto $n$ o 72.744:[9] Heliana da Silva Jatene para a Fundação Cultural de Belém (Fumbel), ex-mulher de Simão Jatene, governador do estado do Pará e de seu mesmo partido, o PSDB; $\quad$ Leonardo Maroja, filho do desembargador João José da Silva Maroja, para a Secretaria de Assuntos Jurídicos (Semaj). Rosa Maria Chaves da Cunha, cunhada de Simão Jatene, para presidente da Codem (Companhia de Desenvolvimento de Belém); $\quad$ Tereza Cativo, ex-secretária especial do governador Jatene, indiciada em inquérito no Superior Tribunal de Justiça (STJ), por acusações de corrupção, no enroladíssimo Caso Cerpasa".

- Clécio Luis Vilhena Vieira - REDE - Macapá.

- Arthur Virgílio do Carmo Ribeiro Neto - PSDB - Manaus - Pai, filho, neto e bisneto de políticos. "Arthur Virgílio do Carmo Ribeiro nasceu em Recife (PE), em junho de 1884. Ingressou na magistratura amazonense em 1905 e atuou em diversas Comarcas do Estado do Amazonas. Foi

\footnotetext{
${ }^{12}$ http://www.fgv.br/cpdoc/acervo/dicionarios/verbete-biografico/soares-filho-firmino

${ }^{13}$ http://gvces.com.br/nepotismo-uma-praga-no-para?locale=pt-br
} 
nomeado desembargador em 1930, presidente do TJAM nos anos de 1937 e 1943, e presidente da Corte Eleitoral amazonense no biênio 1946/1947"14.

- Maria Teresa Saenz Surita - Ex-mulher do Senador Romero Jucá.

- Marcus Alexandre Médici Aguiar Viana da Silva - PT - Rio Branco.

- Hildon Chaves - PSDB - Porto Velho, Grupo Athenas Educacional, que é o maior Grupo Educacional da Região Norte do país ${ }^{15}$.

- Carlos Enrique Amastha - PSB - Palmas. Empresário de origem colombiana ${ }^{16}$.

TABELA

\begin{tabular}{|c|c|c|c|c|}
\hline Capital & Nome do Prefeito & Partido & Família & Família Importa \\
\hline Porto Alegre & Nelson Marchezan Júnior & PSDB & $\begin{array}{c}\text { Filho do ex-deputado } \\
\text { Federal Nelson Marchezan. }\end{array}$ & SIM \\
\hline Florianópolis & Gean Marques Loureiro & PMDB & $\begin{array}{l}\text { Pai Aguinaldo José Loureiro } \\
\text { foi funcionário da ALESC. }\end{array}$ & NÃO \\
\hline Curitiba & Rafael Greca de Macedo & PMN & $\begin{array}{l}\text { Oligarquia familiar histórica } \\
\text { Macedo }\end{array}$ & SIM \\
\hline São Paulo & João Doria & PSDB & $\begin{array}{l}\text { Oligarquia familiar histórica } \\
\text { Doria }\end{array}$ & SIM \\
\hline Rio de Janeiro & Marcelo Crivella & PRB & $\begin{array}{l}\text { Família de chefes religiosos } \\
\text { evangélicos Macedo Bezerra }\end{array}$ & SIM \\
\hline Belo Horizonte & Alexandre Kalil & PHS & $\begin{array}{l}\text { Filho do ex-presidente do } \\
\text { Clube Atlético Mineiro }\end{array}$ & SIM \\
\hline Vitória & $\begin{array}{l}\text { Luciano Santos Rezende } \\
\text { Vitória }\end{array}$ & PPS & & NÃO \\
\hline
\end{tabular}

14 http://www.amazonianarede.com.br/tjam-inaugura-predio-anexo-com-homenagem-a-arthur-virgilio-do-carmoribeiro-avo-do-prefeito-de-manaus/

${ }^{15}$ http://blog.drhildon.com.br/hildonchaves/

${ }^{16}$ http://www.bygu.com.br/video/biografia-carlos-amastha-parte-01/HCzotiliCLE//gurupi/tocantins 


\begin{tabular}{|c|c|c|c|c|}
\hline Campo Grande & Marcos Marcello Trad & PSD & Família política Trad & SIM \\
\hline Cuiabá & Emanuel Pinheiro & PMDB & $\begin{array}{l}\text { Filho do Deputado Emanuel } \\
\text { Pinheiro }\end{array}$ & SIM \\
\hline Goiânia & Iris Rezende Machado & PMDB & $\begin{array}{l}\text { Mulher Iris foi Deputada } \\
\text { Federal }\end{array}$ & $\operatorname{SIM}$ \\
\hline Salvador & $\begin{array}{c}\text { Antonio Carlos Magalhães } \\
\text { Neto }\end{array}$ & DEM & $\begin{array}{l}\text { Oligarquia familiar } \\
\text { Magalhães }\end{array}$ & SIM \\
\hline Aracaju & Edvaldo Nogueira & PCdoB & & NÃO \\
\hline Maceió & Rui Soares Palmeira & PSDB & Oligarquia familiar Palmeira & SIM \\
\hline Recife & $\begin{array}{l}\text { Geraldo Júlio de Mello } \\
\text { Filho }\end{array}$ & PSB & & NÃO \\
\hline João Pessoa & Luciano Cartaxo Pires de Sá & PSD & & NÃO \\
\hline Natal & Carlos Eduardo Alves & PDT & Oligarquia familiar Alves & $\operatorname{SIM}$ \\
\hline Fortaleza & $\begin{array}{c}\text { Roberto Cláudio Rodrigues } \\
\text { Bezerra }\end{array}$ & PDT & $\begin{array}{l}\text { Filho do Reitor Roberto } \\
\text { Cláudio Frota Bezerra }\end{array}$ & $\operatorname{SIM}$ \\
\hline Teresina & $\begin{array}{l}\text { Firmino da Silveira Soares } \\
\text { Filho }\end{array}$ & PSDB & & NÃO \\
\hline São Luís & $\begin{array}{c}\text { Edivaldo de Holanda Braga } \\
\text { Júnior }\end{array}$ & PDT & Pai foi parlamentar & SIM \\
\hline Belém & $\begin{array}{l}\text { Zenaldo Rodrigues } \\
\text { Coutinho Júnior }\end{array}$ & PSDB & Nomeou irmão Secretário & SIM \\
\hline Macapá & Clécio Luis Vilhena Vieira & REDE & & NÃO \\
\hline Manaus & $\begin{array}{c}\text { Arthur Virgílio do Carmo } \\
\text { Ribeiro Neto }\end{array}$ & PSDB & $\begin{array}{c}\text { Pai Senador avô } \\
\text { Desembargador e filho } \\
\text { Deputado }\end{array}$ & SIM \\
\hline Boa Vista & Maria Teresa Saenz Surita & PMDB & Ex-mulher do Senador Jucá & SIM \\
\hline Rio Branco & Marcus Médici & PT & & NÃO \\
\hline Porto Velho & Hildon de Lima Chaves & PSDB & & NÃO \\
\hline Palmas & Carlos Enrique Amastha & PSB & & NÃO \\
\hline
\end{tabular}




\section{CONSIDERAÇÕES FINAIS}

Dos 26 Prefeitos eleitos nas eleições de 2016, dezesseis (16) apresentam capitais sociais familiares e possuem estruturas familiares os apoiando nas suas trajetórias, enquanto dez (10) não apresentam estruturas familiares nas suas trajetórias políticas, o que mais uma vez confirma a correlação positiva entre estruturas de parentesco e poder político como um importante fator de sucesso eleitoral e político no Brasil. Logo, cerca de $61,5 \%$ do total de prefeitos eleitos das capitais em 2016 são vinculados às famílias políticas, quase dois terços do total, uma taxa semelhante a composição de Senadores pertencentes às mesmas famílias políticas. Muitas vezes os políticos sem famílias importantes no campo político também dependeram de alianças e apadrinhamentos com grandes famílias políticas.

Dos partidos políticos associados ao fenômeno do familismo no Brasil, o PSDB apresenta quatro (4) prefeitos com fortes relações familiares e dois(2) sem. Do PMDB três (3) prefeitos apresentam relações familiares e um (1) não. Os três (3) prefeitos eleitos pelo PDT apresentam relações familiares. Logo, alguns partidos políticos apresentam maiores concentrações de candidatos associados a famílias políticas porque alguns partidos políticos apresentam maiores afinidades com os interesses e agendas das oligarquias familiares.

Em termo de regiões brasileiras, o Sul apresenta dois prefeitos em três vinculados às famílias políticas, o Sudeste apresenta três em quatro, o Nordeste apresenta cinco em nove, o Norte apresenta três em sete, o Centro-Oeste três em três, como verificamos trata-se de fenômeno nacional e distribuído em todas regiões brasileiras.

Outras investigações e análises podem ser feitas com este grupo de 26 prefeitos eleitos em 2016. Prosopografias familiares, casamentos, ocupações e profissões, trajetórias sociais e políticas, comportamentos partidários, etnicidades, história social, econômica e política de suas origens familiares, pesquisas e estudos genealógicos mais detalhados. 